Discussion Paper No. 519

TARIFFS, TIME PREFERENCE, AND THE CURRENT ACCOUNT UNDER WEAKLY NONSEPARABLE PREFERENCES

Shinsuke Ikeda

October 2000

The Institute of Social and Economic Research Osaka University

6-1 Mihogaoka, Ibaraki, Osaka 567-0047, Japan 


\title{
Tariffs, Time Preference, and the Current Account under Weakly Nonseparable Preferences*
}

\author{
Shinsuke IKEDA ${ }^{\dagger}$
}

The Institute of Social and Economic Research, Osaka University

October 2000

\begin{abstract}
Incorporating weakly nonseparable preferences into the familiar time-preference model, we emphasize a role of steady-state welfare changes in determining the effect of permanent tariffs on the current account. The effect consists of: a welfare effect, due to steady-state welfare changes, which is negative (positive) when preferences toward imports are more (less) wealth-enhanced than toward exports; and a substitution effect, which occurs only with initial distortion. Even without initial distortion, a marginal tariff has a first-order welfare effect on the current-account. Its sign does not depend on whether impatience is increasing or decreasing in wealth.
\end{abstract}

Keywords: Tariff; time preference; weakly nonseparable preferences; current account

JEL classification: F41; F32; F13

*Forthcoming in Review of International Economics.

$\dagger$ Correspondence. Shinsuke Ikeda, The Institute of Social and Economic Research, Osaka University, 6-1 Mihogaoka, Ibaraki, Osaka 560-0047, Japan. Telephone: +81-66879-8568. Fax: +81-6-6878-2788. E-mail: ikeda@iser.osaka-u.ac.jp 


\section{Introduction}

Together with the increased importance of tariffs as a commercial policy in international trade arrangements (e.g., the Uruguay GATT round), the last fifteen years have witnessed the reexamination of the macroeconomic effects of tariffs using modern dynamic optimizing models. The first and still most important contribution is Razin and Svensson (1983). Using a twoperiod model, they show how a permanent rise in tariffs affects savings and the current account by changing the interest rate in the utility terms if the present subutility function differs from the future one. With the resultant preference-shift, a permanent tariff affects the price indices differently for present and future expenditures, changes the real interest rate, and thereby influences savings through a substitution effect. ${ }^{1}$

Their seminal work stimulated many subsequent studies, ${ }^{2}$ though it relies on some restrictive assumptions. First of all, by using exogenous timevarying subutility functions, the preference-shifting is incorporated in the form of an externality to consumers. ${ }^{3}$ A more natural and reasonable modeling would entail endogenous preference-shifting. Secondly, as Svensson and Razin (1983) show using a two-period framework, a change in the terms of trade affects savings through (i) a substitution effect, due to compensated demand shifts, and (ii) a welfare effect, owing to changes in welfare. However, Razin and Svensson (1983) assume that preferences are homothetically separable over time, thereby implicitly neglecting a welfare effect.

To ease the restrictions, we incorporate a type of preference nonseparability to examine the effects of a permanent change in tariffs for a small country model. By extending the familiar time-preference model, à la Uzawa (1968) and Epstein and Hynes (1983), consumer preferences are specified as weakly nonseparable, in the sense that the intratemporal marginal rate of substitution between two goods, imported and exported goods, depends on

\footnotetext{
${ }^{1}$ In the case of a temporary rise in tariffs, it always raises the real interest rate, increases saving, and hence improves the current account even if the subutility function is timeinvariant. See Razin and Svensson (1983).

${ }^{2}$ For example, Van Wijnbergen (1987) focuses on a real wage rigidity to derive the effects of permanent and temporary tariffs which are distinct from what Svensson and Razin obtain. O'Rourke (1989) argues that a permanent tariff reduction worsens the current account under a short-run sectoral immobility of capital. Ostry (1990) shows that in the presence of initial tariffs, temporary tariffs can worsen the current account through a temporary income reduction which is magnified by the initial distortion.

${ }^{3}$ For detailed discussions, see also Svensson and Razin (1983), particularly p.108.
} 
future consumption through current welfare. Relative preferences toward the two goods then depend on current welfare and hence on current wealth. Put otherwise, when wealth increases, preferences toward one good can be more or less enhanced than those toward the other good. With the preference structure, a permanent rise in import tariffs induces a change in steady-state welfare and wealth so as to make preferences shift away from imports in favor of exports. The current account must adjust in the interim run to bring about the steady-state welfare change. Our main interest is to focus on this channel which is neglected in the literature. The resultant current-account adjustment is generated by endogenous preference shifts.

Weakly nonseparable preferences are considered in endogenous time preference models by Lucas and Stokey (1984), Judd (1985), Epstein, Ham, and Zin (1988), Shi (1994), and Ikeda (2000a, b). Shi (1994) conducts the most systematic analysis on this topic. He characterizes the consumption-leisure choice under weakly nonseparable preferences to discuss implications of distortionary taxation on capital and/or labor. His key finding is that even a marginal tax can affect steady-state welfare. Our idea is to apply this property to the analysis of tariffs in a two-commodity framework. My companion paper (Ikeda (2000a)) examines the effect of a terms-of-trade deterioration using a model similar to the one in this paper. In contrast to the literature (e.g., Obstfeld (1982)), it shows that the Harberger-Laursen-Metzler effect can occur even with increasing impatience. It will turn out that weakly nonseparable preferences make more difference when they are applied to the analysis of tariffs, especially the effect of a marginal increase in tariffs without initial distortion.

Based on the usual assumption that the degree of impatience measured by time preference is increasing in current wealth, we first show that a permanent rise in tariffs raises or lowers steady-state welfare, depending on whether preferences toward exports are more or less wealth-enhanced than those toward imports. As in Svensson and Razin (1983), the effect on the current account is decomposed into two, possibly offsetting effects: (i) a substitution effect and (ii) a welfare effect. (i) has a first-order magnitude only with initial distortion and is positive, whereas (ii) has a first-order negative (positive) effect even without initial tariffs when preferences toward imported goods are more (less) wealth-enhanced than toward exports. This property is in sharp contrast to what Razin and Svensson (1983) obtain: in their model a marginal tariff without initial distortion can have a first-order substitution effect but no welfare effect. We will clarify how their result depends on the 
two restrictive assumptions we pointed out at the outset. Nevertheless, the working of our model will turn out to be economically very similar to that of Razin and Svensson's model: in both of the models, a permanent tariff without initial distortion improves (deteriorates) the current account only when relative preferences toward imports are, endogenously or exogenously, weakened (enhanced) in the future (i.e., in the new steady state), in which case the import tariff makes present goods more (less) expensive than future ones. Our contribution lies in that the result here is obtained by focusing on a welfare effect in an infinite-horizon model with endogenous preference shifting.

The Uzawa-type time-preference is sometimes criticized for its unappealing feature that the property of dynamics depends crucially on the assumption of increasing impatience (e.g., Svensson and Razin (1983) and Mansoorian (1993)). To address this issue, we also examine the case of decreasing impatience, showing that the assumption in this regard does not play such a crucial role under weakly nonseparable preferences. In particular, without initial distortion, the sign of the effect on the current account depends solely on whether preferences toward exports are more or less wealth-enhanced than toward imports, but not on whether impatience is increasing or decreasing in wealth, i.e., not on whether preferences toward present goods are more or less wealth-enhanced than toward future goods.

There are a couple of studies which have incorporated intertemporally dependent preferences to analyze the effect of permanent tariffs. By the straightforward application of Uzawa's time-preference model, Engel and Kletzer (1986) show that a first-order distortion caused by a tariff leads to an improvement in the current account. Mansoorian (1993) emphasizes habit persistence as an important determinant of the effect of permanent tariffs. Our study can be differentiated from these studies in several points. First of all, they invariably assume identically weakly separable preferences, excluding implicitly a welfare effect which we emphasize. Secondly, their arguments are limited to the case of non-marginal tariffs. In our model, even marginal tariffs without initial tariffs always have a first-order (welfare) effect on saving. Thirdly, a permanent tariff here can increase steady-state welfare, 
whereas in their model tariffs harm it. ${ }^{4,5}$

The rest of the paper is organized as follows. Section 2 presents our analytical framework and derives the equilibrium dynamics. In section 3, the effects of a permanent increase in tariffs are examined. In section 4, the case of decreasing impatience is examined. Section 5 concludes the paper.

\section{The analytical framework}

\subsection{The model}

Consider a small open economy populated with infinitely-lived identical agents. They consume domestic goods $d$ and foreign goods $f$. The economy is endowed with constant units $y$ of the domestic good and nothing of the foreign good at each instant. All the foreign-good consumption $f$ is thus imported from abroad. By the small-country assumption, the relative price $p$ of the foreign good in terms of the domestic one is exogenously given. An import tariff $\tau$ is levied on consumption $f .{ }^{6}$ The government just refunds the tariff revenue to consumers in the lump-sum manner. The representative agent holds non-human wealth in the form of bonds $b$. Bonds can be either purchased or issued freely at a constant interest rate $r$ in the international market.

Consumers' preferences are characterized by endogenous utility-discounting and weak nonseparability. Their lifetime utility $U$ is specified as:

$$
U(0)=\int_{0}^{\infty} u(d(t), f(t)) \exp \left(-\int_{0}^{t} \theta(d(s), f(s)) \mathrm{d} s\right) \mathrm{d} t
$$

${ }^{4}$ As in these existing models focusing on consumer preferences, we assume away any supply-side adjustments. For this point, see Sen and Turnovsky (1989), Gavin (1991) and Turnovsky (1991). See also Engel and Kletzer (1990), in which an overlapping-generations model is developed to examine the effect of a tariff through intergenerational redistribution of income that is caused by factor-price changes and by the distribution of tariff revenue.

${ }^{5}$ Surprisingly, empirical research on the current-account effects of tariffs is very few and the result is controversial. For example, Dornbusch (1987) reports that it is positive, whereas Ostry and Rose (1992) show that tariff changes have no significant effects on macroeconomic variables such as the real trade balance. See also Backus et al. (1994), which report that signs of correlation between the terms of trade and the trade account differ internationally.

${ }^{6} \mathrm{~A}$ part of domestic-good consumption $d$ may also be imported if the representative agent holds positive net foreign assets. Throughout the paper, however, we restrict our attention to import tariffs which are imposed only on $f$. 
where $u(\cdot, \cdot)$ represents a felicity function and where $\theta(\cdot, \cdot)>0$ is a discounting function. We assume:

$$
\theta_{d}, \theta_{f} \geqq 0 \text { and } \theta_{d}+\theta_{f}>0,
$$

where $\theta_{d}=\partial \theta / \partial d$, etc. This assumption implies increasing marginal impatience in the sense that time preferences are increasing in current welfare. ${ }^{7}$

When we define the generating function $g$ as

$$
g(d, f, \phi)=u(d, f)-\phi \theta(d, f),
$$

where $\phi(t)$ represents the lifetime utility $U(t)$ from the consumption stream after time $t, g$ generates $\phi$ by the law of motion,

$$
\dot{\phi}=-g(d, f, \phi) \text { s.t. } \lim _{t \rightarrow \infty} \phi(t) \exp \left(-\int_{0}^{t} \theta(d(s), f(s)) \mathrm{d} s\right)=0,
$$

where a dot represents the time derivative. Note that $g_{d}$ and $g_{f}$ equal the current-value marginal utilities of $d(t)$ and $f(t)$ respectively, defined in terms of the Voltera derivative. We assume $g_{d}>0$ and $g_{f}>0$. The marginal rate of substitution between $d(t)$ and $f(t)$ is then given by the ratio of $g_{f}$ and $g_{d}$, i.e., $\mathrm{d} d(t) /\left.\mathrm{d} f(t)\right|_{U(0)=\text { const. }}=\left(g_{f} / g_{d}\right)(d(t), f(t), \phi(t))$. The preferences are weakly nonseparable if $g_{f}(t) / g_{d}(t)$ really depends on $\phi(t)$ and hence on the consumption stream after $t$.

To characterize weak nonseparability, we follow Shi (1993) in introducing a nonseparability index $\xi$ as

$$
\xi(d, f, \phi) \equiv \frac{1}{g_{f} / g_{d}} \frac{\partial\left(g_{f} / g_{d}\right)}{\partial \phi}=\frac{\theta_{d}}{g_{d}}-\frac{\theta_{f}}{g_{f}} .
$$

By definition, the weak nonseparability of preferences is captured by a nonzero $\xi$ and weak separability by $\xi=0 .{ }^{8}$ A positive (negative) $\xi$ implies that a rise in lifetime utility shifts preferences away from consumption $d$ to $f$ ( $f$ to $d)$. When $\xi>(<) 0$, preferences toward foreign goods $f$ are referred to as more (less) wealth-enhanced than those toward $d$. For an alternative interpretation, the index can be rewritten as $\xi(d, f, \phi)=\frac{\theta_{d} \theta_{f}}{g_{d} g_{f}}\left(\frac{u_{f}}{\theta_{f}}-\frac{u_{d}}{\theta_{d}}\right)$. With

\footnotetext{
${ }^{7}$ See Lucas and Stokey (1984). This implication will be seen explicitly in (10) below.

${ }^{8}$ For example, consider three cases: (i) $\theta$ is constant (time-additive preferences); (ii) $u$ is constant (e.g., Epstein and Hynes (1983)); and (iii) $\theta$ is a transform of $u$ (e.g., Uzawa $(1968))$. In these cases, in which preferences are weakly separable, $\xi$ indeed equals zero.
} 
a positive (negative) $\xi$, therefore, the relative elasticities of $u$ to $\theta$ with respect to $f$ are larger (smaller) than those with respect to $d$. As shown later, under weakly nonseparable preferences, such a discrepancy in the relative elasticities allows a change in tariffs to affect steady-state welfare $u / \theta$.

As for the second-order derivatives of $g$, we assume: $g_{d f}=0$ and

$$
g_{d d}<0, g_{f f}<0, \frac{\theta g_{d d}}{g_{d}^{2}}<\xi<-\frac{\theta g_{f f}}{g_{f}^{2}} .
$$

Inequality (3) ensures the local concavity of consumers' preferences. ${ }^{9}$

Consumers maximize lifetime utility (1) subject to: (i) the flow budget constraint,

$$
\dot{b}(t)=r b(t)+y-d(t)-(p+\tau(t)) f(t)+x(t),
$$

where $x$ represents a lump-sum transfer from the government; (ii) the initial condition, $b_{0}=$ given; and (iii) the no-Ponzi game condition, $\lim _{t \rightarrow \infty} \exp (-r t) b(t) \geq$ 0 . Letting $\lambda$ denote the current-value shadow price of savings, the first-order conditions are given by:

$$
\begin{aligned}
& g_{d}(d, \phi)\left(\equiv u_{d}(d, f)-\phi \theta_{d}(d, f)\right)=\lambda, \\
& \frac{g_{f}(f, \phi)}{g_{d}(d, \phi)}=p+\tau \\
& \dot{\lambda}=(\theta(d, f)-r) \lambda \\
& \dot{\phi}=-g(d, f, \phi) .
\end{aligned}
$$

To eliminate $\lambda$ from the Euler condition (7), define the rate of time preference $\rho^{d}$ with respect to $d$ as $\rho^{d}=-\mathrm{d} \ln \Omega^{d}(t) /\left.\mathrm{d} t\right|_{\dot{d}=0}$, where $\Omega^{d}(t) \equiv$ $g_{d}(d(t), \phi(t)) \exp \left(-\int_{0}^{t} \theta(d(s), f(s)) \mathrm{d} s\right)$ represents the present-value marginal utility of $d$. Then, from (5), (7) can be rewritten as

$$
\dot{d}=-\frac{g_{d}}{g_{d d}}\left(r-\rho^{d}(d, f, \phi)\right),
$$

where

$$
\rho^{d}(d, f, \phi)=\theta(d, f)-\frac{\theta_{d}(d, f)}{g_{d}(d, \phi)} g(d, f, \phi) .
$$

${ }^{9}$ See Shi (1994) for the proof. The assumption that $g_{d f}=0$ is made just for brevity. 
The rate of time preference $\rho^{f}$ with respect to $f$ can also be defined in the same manner. From (8) and (10), in the steady state, the rates of time preference equal the discount rate $\theta$.

The government follows the balanced-budget principle:

$$
\tau(t) f(t)=x(t) .
$$

Throughout the paper the government is assumed to keep the time path of $\tau(t)$ flat after the initial point in time. Given an endogenously-determined $f(t), x(t)$ is determined to satisfy this equation. Combining the budget equation for the government with consumers' one yields the balance of payment equation,

$$
\dot{b}(t)=r b(t)+y-d(t)-p f(t) .
$$

\subsection{Equilibrium dynamics}

Given the initial bond stock, the equilibrium dynamics for $(b, d, f, \phi)$ are completely described by (8), (6), (9), (11), and the no-Ponzi game condition. The steady-state equilibrium, $\left(b^{*}, d^{*}, f^{*}, \phi^{*}\right)$, is determined by the following equations:

$$
\begin{aligned}
& \left(\rho^{d}\left(d^{*}, f^{*}, \phi^{*}\right)=\right) \theta\left(d^{*}, f^{*}\right)=r, \\
& \phi^{*}=u\left(d^{*}, f^{*}\right) / r \\
& \frac{g_{f}\left(f^{*}, u\left(d^{*}, f^{*}\right) / \theta\left(d^{*}, f^{*}\right)\right)}{g_{d}\left(d^{*}, u\left(d^{*}, f^{*}\right) / \theta\left(d^{*}, f^{*}\right)\right)}=p+\tau, \\
& r b^{*}=d^{*}+p f^{*}-y .
\end{aligned}
$$

In the above, (12) represents $\dot{d}=0$ where (10) and $g^{*}=0$ are substituted successively into (9). (13) comes from (2) and (12) with $g^{*}=0$. (14) is obtained by substituting (12) and (13) into (6). (15) represents $\dot{b}=0$ (see (11)).

(12) and (14) jointly determine $d^{*}$ and $f^{*} \cdot \phi^{*}$ and $b^{*}$ are then given by (13) and (15), respectively. Figure 1 illustrates the determination of the steady-state equilibrium. Schedules $R R^{\prime}$ and $F F^{\prime}$ represent (12) and (14), respectively: $R R^{\prime}$ represents the locus of $\left(d^{*}, f^{*}\right)$ which equalizes the steady-state rate of time preference to the world interest rate; and $F F^{\prime}$ is the 
locus along which the intratemporal marginal rate of substitution equals the tariff-adjusted relative price. The $R R^{\prime}$-schedule, say the steady-state time preference curve, necessarily has a negative slope, whereas the slope of $F F^{\prime}$ can be of either sign. The figure depicts a normal case in which $F F^{\prime}$ is positively sloping. The steady-state consumption $\left(d^{*}, f^{*}\right)$ is determined at the intersection point $E$ of schedules $R R^{\prime}$ and $F F^{\prime}$. Given this, the external balance condition (15) is depicted as schedule $B B^{\prime}$, which goes through point $E$ with slope $-1 / p$. Its horizontal intercept, point $B$, represents $r b^{*}+y$ and hence gives the steady-state bond stock $b^{*}$.

We can depict the effect of an initial tariff $\tau$ by using a line segment $T T^{\prime}$ going through point $E$ with slope $-1 /(p+\tau)$. From $(14)$, schedule $T T^{\prime}$ can be regarded as the linear approximation of the steady-state indifference curve around point $E:\left\{\left(d^{*}, f^{*}\right) \mid u\left(d^{*}, f^{*}\right) / \theta\left(d^{*}, f^{*}\right)=\right.$ utility at $\left.E\right\}$. The slope of the schedule, $-1 /(p+\tau)\left(=-g_{d} / g_{f}\right.$ from (14)), is smaller or larger in magnitude than the gradient at point $E$ of schedule $R R^{\prime}$, i.e., $-\theta_{d} / \theta_{f}$, as $\xi$ is positive or negative. In figure $1, \xi$ is assumed to be positive. Note also that the gradient of curve $R R^{\prime}$ at point $E$ is assumed to be larger in magnitude than $1 / p$, the slope of the external balance line $B B^{\prime}$. It will be shown later that the relative magnitudes of the gradients of three schedules $R R^{\prime}, T T^{\prime}$, and $B B^{\prime}$, determine the signs of the effects of a tariff change on $\phi^{*}$ and $b^{*}$.

To obtain the local dynamic system for $X \equiv(d, \phi, b)$, solve (6) for $f$, which can be substituted into (8), (9), and (11). By linearizing the resulting system around the steady state, we have $\dot{X}(t)=A \hat{X}(t)$;

$$
A \equiv\left(\begin{array}{ccc}
-\frac{\xi g_{f}^{2}}{g_{f f}} & \frac{g_{d}}{g_{d d}}\left(\frac{g_{f}^{2} \xi^{2}}{g_{f f}}+\frac{r \theta_{d}}{g_{d}}\right) & 0 \\
-g_{d}\left\{1+(p+\tau)^{2} \frac{g_{d d}}{g_{f f}}\right\} & r+\frac{\xi g_{f}^{2}}{g_{f f}} & 0 \\
-1-p(p+\tau) \frac{g_{d d}}{g_{f f}} & p \frac{\xi g_{f}}{g_{f f}} & r
\end{array}\right),
$$

where the hats placed above the variables denote deviations from their steadystate values, e.g., $\hat{d}(t)=d(t)-d^{*}$.

We can show that the linear system has two positive and one negative roots, with the negative one being given by

$$
\omega \equiv \frac{r-\sqrt{r^{2}+\frac{4 g_{d}^{2} g_{f}^{2}}{g_{d d} g_{f f}} \Psi}}{2},
$$


where

$$
\Psi=-\left\{\xi^{2}+\frac{r \theta_{d} \theta_{f}}{g_{d} g_{f}}\left(\frac{g_{d d}}{\theta_{d} g_{d}}+\frac{g_{f f}}{\theta_{f} g_{f}}\right)\right\},
$$

which can be shown to be positive under increasing impatience and (3) (see appendix $\mathrm{A}$ for the proof). It follows that the relevant dynamic system exhibits saddle point stability.

The resultant saddle trajectories can be derived from the eigen vectors associated with (16) as

$$
\begin{aligned}
& \dot{b}(t)=\omega \hat{b}(t), \hat{b}(0)=b_{0}-b^{*}, \\
& \hat{d}(t)=\frac{(r-\omega) g_{f}^{2}}{g_{f f} \Delta}\left(\xi+\frac{g_{f f}(r-\omega)}{g_{f}^{2}}\right) \hat{b}(t), \\
& \hat{f}(t)=\frac{(r-\omega) g_{f} g_{d}}{g_{f f} \Delta}\left(\frac{g_{d d}(r-\omega)}{g_{d}^{2}}-\xi\right) \hat{b}(t), \\
& \hat{\phi}(t)=\frac{(r-\omega) g_{d}}{\Delta}\left\{1+(p+\tau)^{2} \frac{g_{d d}}{g_{f f}}\right\} \hat{b}(t),
\end{aligned}
$$

where

$$
\Delta=\frac{g_{f}^{2}}{g_{f f}}\left[\xi+\frac{g_{f f}(r-\omega)}{g_{f}^{2}}+\frac{p}{p+\tau}\left\{\frac{g_{d d}(r-\omega)}{g_{d}^{2}}-\xi\right\}\right],
$$

which is positive under the concavity assumption (3).

(18) gives monotonic dynamics for state variable $b$. Given the dynamics, transitional paths for $d, f$, and $\phi$ are determined on stable arms (19), (20), and (21), respectively. With (3), the saddle trajectories are all positivelysloping, implying that both consumption goods are normal. In figure 1 , the stable arm for $(\hat{d}, \hat{f})$ obtained from (19) and (20) is depicted by a positivelysloping schedule $S S^{\prime}$. This could be regarded as the Engel-curve. 


\section{The effect of a permanent increase in tariffs}

Let us examine the effects of an unanticipated, permanent increase in the tariff $\tau$ at the initial point in time, $t=0 .{ }^{10}$ Since the equilibrium dynamics along the saddle trajectory are monotonic, the sign of the current-account effect in the short run is the same as that of the steady-state effect on net foreign assets.

Formally the steady-state effect of a permanent rise in $\tau$ can be derived from (12) through (15) as

$$
\begin{aligned}
& \frac{\mathrm{d} d^{*}}{\mathrm{~d} \tau}=\frac{r \theta_{f}}{g_{f}^{2} \Psi}>0, \\
& \frac{\mathrm{d} f^{*}}{\mathrm{~d} \tau}=-\frac{r \theta_{d}}{g_{f}^{2} \Psi}<0, \\
& \frac{\mathrm{d} \phi^{*}}{\mathrm{~d} \tau}=-\frac{\xi}{\Psi(p+\tau)} \gtreqless 0 \text { as } \xi \lesseqgtr 0, \\
& \frac{\mathrm{d} b^{*}}{\mathrm{~d} \tau}=\frac{p}{g_{f} \Psi(p+\tau)}\left(\frac{\tau \theta_{f}}{p g_{f}}-\xi\right) \gtreqless 0 \text { as } \frac{\tau \theta_{f}}{p g_{f}} \gtreqless \xi
\end{aligned}
$$

(22) and (23) reveal that an increase in $\tau$ shifts consumption from $f^{*}$ to $d^{*}$. From (24), the effect on $\phi^{*}$ can be either positive or negative according to whether $d$ is more or less wealth-enhanced than $f$. This is because when $\xi<(>) 0$, i.e., when preferences toward $d$ are more (less) wealth-enhanced than those toward $f$, the relative elasticities of $u$ to $\theta$ with respect to $d$ are larger (smaller) than those with respect to $f$. Given that any changes in $\left(d^{*}, f^{*}\right)$ should take place to keep $\theta$ equal to $r$, the positive effect of the increase in $d^{*}$ given by (22) on $u^{*} / \theta^{*}$ dominates (is dominated by) the negative effect of the decrease in $f^{*}$ shown by (23). Intuitively, in the long run, welfare adjusts so as to promote consumption substitution from $f^{*}$ to $d^{*}$ : when preferences toward $d^{*}$ are more (less) wealth- and hence welfare-enhanced than toward $f^{*}$, steady-state welfare increases (decreases) to enhance the preferences toward $d^{*}$.

\footnotetext{
${ }^{10}$ Recent empirical studies report that average tariff-rates contain unit roots in many countries (e.g., Gardner and Kimbrough (1989), Gardner, Slottje, and Kimbrough (1992), and Bohara and Kaempfer (1994)). That is, tariff shocks can be actually viewed as permanent.
} 
(25) reveals that the effect on $b^{*}$ depends crucially on the relative magnitudes of $\tau \theta_{f} / p g_{f}$ and $\xi$, which capture the following effects on spending, respectively: (i) a substitution effect, caused by compensated consumption shifts; and (ii) a welfare effect, due to changes in steady-state welfare given by (24). A substitution effect is proportionate to initial tariff $\tau$ and weakly positive, whereas the welfare effect can take either sign. When $\xi$ is negative, a permanent rise in $\tau$ improves $b^{*}$ and hence the current account. In the case of a positive $\xi$, in contrast, the same policy may deteriorate them due to a negative welfare effect. ${ }^{11}$

These steady-state effects can be illustrated completely by using the schedules in figure 1. From the definition of $\xi$ and (6), we have $\tau \theta_{f} / p g_{f} \gtreqless \xi$ as $1 / p \gtreqless \theta_{d} / \theta_{f}$ : whether a substitution effect is stronger or weaker than a welfare effect is shown in the figure by whether the slope of the external balance line $B B^{\prime}$ is larger or smaller than the gradient at the steady-state point of the steady-state time preference curve $R R^{\prime}$. Recall also that the signs of $\xi$ and hence of a welfare effect are determined by the relative gradients of schedules $R R^{\prime}$ and $T T^{\prime}$ (see section 2.2). We can thus taxonomize the effect of tariffs on $\left(b^{*}, \phi^{*}\right)$ according to possible orders for the gradients of schedules $B B^{\prime}, R R^{\prime}$, and $T T^{\prime}$. For example, figure 2 depicts the case in which $\xi>\tau \theta_{f} / p g_{f}>0$ (i.e., $\left.\theta_{d} / \theta_{f}\left(=\left|\operatorname{grad} R R^{\prime}\right|\right)>1 / p\left(=\left|\operatorname{grad} B B^{\prime}\right|\right)>g_{d} / g_{f}\left(=\left|\operatorname{grad} T T^{\prime}\right|\right)\right)$. An increase in $\tau$ shifts the $F F^{\prime}$ schedule to the right, thereby bringing the steadystate point from point $E_{0}$ to $E_{1}$. Since point $E_{1}$ is located below $T T^{\prime}, \phi^{*}$ is reduced by the tariff change. With schedule $B B^{\prime}$ shifting from $E_{0} B_{0}$ to $B_{1} B_{1}^{\prime}$, $b^{*}$ changes from $B_{0}$ to $B_{1}$. Point $E_{2}$, the intersection of the new $F F^{\prime}$-schedule and the $T T^{\prime}$-curve, represents compensated consumption which generates the initial utility at point $E_{0}$. Point $B_{2}$, therefore, gives net foreign assets which are required to maintain the initial living standard. The effect on net foreign assets is composed of a substitution effect, $B_{0} \rightarrow B_{2}$, and a welfare effect, $B_{2} \rightarrow B_{1}$. In the present case, $b^{*}$ and hence the current account deteriorate due to a dominant negative welfare effect.

${ }^{11}$ Formally welfare and substitution effects can be defined by using:

$$
\phi^{*}=u\left(d^{*}, f^{*}\right) / \theta\left(d^{*}, f^{*}\right) \text { and } \frac{g_{f}\left(f^{*}, \phi^{*}\right)}{g_{d}\left(d^{*}, \phi^{*}\right)}=p+\tau,
$$

which can be obtained from (12) to (14). From the equations above, consumption and hence total spending $d^{*}+p f^{*}$ (of the country) can be solved as functions of $p+\tau$ and $\phi^{*}$. The effect of $p+\tau$ on the spending function is a substitution effect and that of $\phi^{*}$ a welfare effect. For more detailed discussions, see Ikeda (2000a). 
Note that even a marginal tariff from no initial distortion has a firstorder welfare effect whereas there is no first-order substitution effect in the absence of initial tariffs. This property is in marked contrast to what is obtained by Razin and Svensson (1983): they show that without initial tariffs there is a first-order substitution effect but no welfare effect. Their result comes from two critical assumptions. First of all, they assume that subutility functions are time-varying, for which case a permanent tariff affects the relative prices of present and future expenditures, changes the real interest rate, and thereby has a first-order intertemporal substitution effect. ${ }^{12}$ Secondly, in their model, intertemporal preferences are assumed to be homothetically, and hence weakly separable, so that there is no welfare effect. In contrast, instead of assuming exogenous time-varying subutility functions, ${ }^{13}$ we have endogenized a preference-shift by incorporating weakly nonseparable preferences into a model with a time-invariant instantaneous utility function. This produces a first-order welfare effect on one hand, and makes a substitution effect disappear on the other hand.

Notwithstanding the contrast, however, the resultant relationship between preference-shifting and the current-account effect is fairly consistent with what Razin and Svensson premise: in both of the models, a permanent, marginal tariff improves (deteriorates) the current account only when relative preferences toward imports are, endogenously or exogenously, weakened (enhanced) in the future (i.e., in the new steady state), in which case a permanent rise in consumers' import prices makes present spending more (less) expensive in real terms than future one. In this sense, our analysis can be regarded as a natural dynamic extension of Razin and Svensson (1983).

A remarkable difference of our result from what is obtained in the literature of dynamic analysis, e.g., Engel and Kletzer (1986) and Mansoorian (1993), also lies in the presence of steady-state effects on welfare without initial distortion. Since they assume weakly separable preferences and time invariant felicity functions, a marginal change in tariffs from zero cannot have a first-order effect on any economic variables. In the case of weak nonseparability, a demand shift caused by the tariff change can affect steady-state welfare and the other variables in the first order. This produces two interesting possibilities which cannot be obtained by the previous literature.

${ }^{12}$ Substitution effects are defined with respect to both intratemporal and intertemporal relative prices. See Svensson and Razin (1983), p.103.

${ }^{13}$ To be more precise, Razin and Svensson assume that consumers choose consumption, taking the time-dependent shift of subutility functions as given, i.e., as an externality. 
First, a rise in tariffs can increase steady-state welfare if preferences toward exportable-good consumption is more wealth-enhanced than toward imports. Second, in contrast to the conventional wisdom, the current account can be worsened if preferences toward imports are sufficiently wealth-enhanced, as shown in figure 2.

As the final remark, distinguish the effect on welfare $\phi(0)$ from that on steady-state welfare. Tariffs in this model cannot enhance welfare $\phi(0)$, even though they improve steady state welfare if $\xi<0$. In fact, $(21),(24)$, and (25) yield

$$
\frac{\mathrm{d} \phi(0)}{\mathrm{d} \tau}=\frac{\tau g_{f}^{2}}{\Psi \Delta(p+\tau)^{2} g_{f f}}\left\{\Psi+\frac{\omega \theta_{d} \theta_{f}}{g_{d} g_{f}}\left(\frac{g_{d d}}{\theta_{d} g_{d}}+\frac{g_{f f}}{\theta_{f} g_{f}}\right)\right\} \leqq 0 .
$$

With initial distortion, therefore, an increase in tariffs is definitely harmful, as in other small country models (e.g., Sen and Turnovsky (1989) and Mansoorian (1993)). Without initial tariffs, a marginal change in tariffs has no first-order effect on welfare. This is natural since there is no other distortion. $^{14}$

\section{The effect of decreasing impatience}

By assuming weak separability, Svensson and Razin (1983) show that (i) increasing (decreasing) impatience is a necessary and sufficient condition for stability (instability) of the steady state, and that (ii) a permanent termsof-trade deterioration worsens (improves) the current account if and only if impatience is decreasing (increasing) in current welfare. From these discussions, they criticize analyses using the Uzawa-type time-preference model for their crucial dependence on the assumption of increasing impatience. How crucially does our result in the previous section depend on the assumption? To examine this issue, let us next consider the case of decreasing impatience:

$$
\theta_{d}, \theta_{f} \leqq 0 \text { and } \theta_{d}+\theta_{f}<0 .
$$

${ }^{14}$ As for initial responses in consumption, from (19) and (21), when $\mathrm{d} b^{*} / \mathrm{d} \tau>0$, domestic-good consumption instantly jumps upward less than in the steady state whereas foreign-good consumption jumps downward more than in the steady state. In contrast, when a negative welfare effect is so large that $\mathrm{d} b^{*} / \mathrm{d} \tau<0$, the initial upward jump in $d$ overshoots its long-run increase while the initial discrete fall in $f$ comes short of its long-run reduction (compare point $E_{01}$ with $E_{1}$ in figure 2). 
Let us begin with the case of no initial distortion: $\tau=0$. From (17), $\Psi$ is negative under decreasing impatience. From the definition of $\omega$, the smaller root $\omega$ thus takes a positive value. ${ }^{15}$ It follows that the equilibrium saddle dynamics are unstable or stable as impatience is decreasing or increasing, ${ }^{16}$ as in Svensson and Razin's finding (i).$^{17}$

The impact effect on current-account $\dot{b}$ at time zero can be obtained from (18) as

$$
\frac{\mathrm{d} \dot{b}(+0)}{\mathrm{d} \tau}=-\omega \frac{\mathrm{d} b^{*}}{\mathrm{~d} \tau}
$$

which implies:

$$
\operatorname{sign} \frac{\mathrm{d} \dot{b}(+0)}{\mathrm{d} \tau}=-\operatorname{sign} \frac{\mathrm{d} b^{*}}{\mathrm{~d} \tau}=-\operatorname{sign} \xi
$$

under decreasing impatience, where the last equality comes from (25).

This reveals that, as in the case of increasing impatience (without initial tariffs), the current-account effect is positive or negative as $\xi$ is negative or positive. In sum, given the sign of nonseparability index $\xi$, the sign of the current-account effect of a permanent increase in tariffs does not depend on whether impatience is increasing or decreasing, in contrast to the Svensson and Razin critique: whether consumer preferences toward "present goods" are more or less wealth-enhanced than toward "future goods," the current account will improve (deteriorate) if the preferences toward exports are more (less) wealth-enhanced than toward imports.

In the presence of initial distortion $\tau>0$, we obtain from (25)

$$
\operatorname{sign} \frac{\mathrm{d} \dot{b}(+0)}{\mathrm{d} \tau}=\operatorname{sign}\left(\frac{\tau \theta_{f}}{p g_{f}}-\xi\right),
$$

implying that, opposite to the case of increasing impatience, a substitution effect, the first term on the right hand side, affects negatively the current account under decreasing impatience. When preferences are weakly separable, therefore, the sign of the current-account effect depends crucially on whether impatience is increasing or decreasing, as is criticized by Svensson

\footnotetext{
${ }^{15}$ We are maintaining the assumption that $g_{d}, g_{f}>0$ and $g_{d d}, g_{f f}<0$.

${ }^{16}$ Even when $\omega$ is positive, the saddle path satisfies the no-Ponzi-game condition.

${ }^{17}$ Following Svensson and Razin (1983, pp. 117-118), we neglect the possibility in the unstable case that the country may get so large to violate the small-country assumption.
} 
and Razin (1983). This crucial dependence is mitigated under weakly nonseparable preferences since the sign of a welfare effect does not depend on that property.

\section{Concluding remarks}

Svensson and Razin emphasize that the current account effects of exportoriented or import-substitution policies, which alter the internal terms of trade, depend crucially on policy-induced changes in wealth and interest rates, rather than on the direct effect of the terms-of-trade change (Svensson and Razin (1983), pp.100-101). However, they, as well as other authors, basically assume weakly separable preferences, thereby implicitly assuming away preference-shifts between exports and imports, caused by "policy-induced changes in wealth." It is this channel that we have focused on in this paper. With weakly nonseparable preferences, a permanent rise in tariffs has a first-order effect on steady-state welfare and thereby on the current account. To obtain credible prediction about the effects of tariffs, empirical research about consumers' preferences is indispensable, especially regarding how the marginal rate of substitution between exports and imports depends on current wealth. ${ }^{18}$

This paper and the companion one (Ikeda, 2000a) imply that weakly nonseparable preferences have an important implication for optimal wealth accumulation. For example, suppose that consumers' preferences toward a certain good are more wealth-enhanced than the other goods. Then, the stronger the preferences toward this luxury-type good are, the more wealth consumers will accumulate. As an interesting application, Ikeda (2000b) examines how intratemporal preferences toward this kind of luxury goods indeed affect economic growth and long-run wealth distribution.

\section{Appendix}

\section{A Positivity of $\Psi$}

To prove the positivity of $\Psi$, we first show the following property:

\footnotetext{
${ }^{18}$ For empirical implications of weakly nonseparable preferences, see Ikeda (2000a).
} 
Property A: Under the regularity assumptions given in the text, $\xi$ must satisfy the following property:

(i) if $\xi>0$, then $\xi^{2}<-\frac{r \theta_{d} g_{f f}}{g_{d} g_{f}^{2}}$;

(ii) if $\xi<0$, then $\xi^{2}<-\frac{r \theta_{f} g_{d d}}{g_{f} g_{d}^{2}}$.

Proof. Since $\xi<\frac{\theta_{d}}{g_{d}}$ by the definition of $\xi$ and the positivity of $g_{f}$, we have $\xi<\frac{\theta_{d}}{g_{d}}$. It follows that when $\xi>0$, we have

$$
\xi^{2}<\frac{\theta_{d}}{g_{d}} \xi<-\frac{\theta_{d}}{g_{d}} \frac{\theta g_{f f}}{g_{f}^{2}},
$$

where the second inequality comes from the third inequality in (3). In the same way the second relation can be proven by using the property that $\xi>\frac{\theta_{f}}{g_{f}}$ even if $\xi<0$ and (3).

From (i) in property A, when $\xi>0$, the definition of $\Psi$ implies

$$
\Psi>\frac{r \theta_{d} g_{f f}}{g_{d} g_{f}^{2}}-\frac{r \theta_{d} \theta_{f}}{g_{d} g_{f}}\left(\frac{g_{d d}}{\theta_{d} g_{d}}+\frac{g_{f f}}{\theta_{f} g_{f}}\right)=-\frac{r \theta_{f} g_{d d}}{g_{d}^{2} g_{f}}>0 .
$$

Similarly when $\xi<0$, it should hold valid that

$$
\Psi>\frac{r \theta_{f} g_{d d}}{g_{d}^{2} g_{f}}-\frac{r \theta_{d} \theta_{f}}{g_{d} g_{f}}\left(\frac{g_{d d}}{\theta_{d} g_{d}}+\frac{g_{f f}}{\theta_{f} g_{f}}\right)=-\frac{r \theta_{d} g_{f f}}{g_{d} g_{f}^{2}}>0 .
$$

\section{Acknowledgments}

The author is grateful to N. Fujimoto, A. Tkachuk, M. Yamaguchi, and two anonymous referees of the Review of International Economics for helpful comments on earlier versions of the paper. A part of this research was conducted while the author visited the Institute of Asian Research and the Department of Economics, the University of British Columbia in 1999. 


\section{References}

Backus, D.K., P.K. Kehoe, and F.E. Kydland, 1994, Dynamics of the trade balance and the terms of trade: the J-curve? American Economic Review 84, 84-103.

Bohara, A.K. and W.H. Kaempfer, 1994, Tariff behavior in five European countries: Further evidence, Economics Letters 45, 213-216.

Dornbusch, R., 1987, External balance correction: Depreciation correction? Brookings Papers on Economic Activity 1, 249-71.

Engel, C. and K. Kletzer, 1986, Tariffs, savings and the current account, NBER working paper no. 1869.

Engel, C. and K. Kletzer, 1990, Tariffs and savings in a model with new generations, Journal of International Economics 28, 71-91.

Epstein, L.G., 1987, The global stability of efficient intertemporal allocations, Econometrica 55, 329-355.

Epstein, L.G., J. Ham, and S.E. Zin, Consumption, labour supply and portfolio choice with time and state nonseparable utility, unpublished, University of Toronto.

Epstein, L.G. and J.A. Hynes, 1983, The rate of time preference and dynamic economic analysis, Journal of Political Economy 91, 611-625.

Frenkel, J.A. and A. Razin, 1992, Fiscal Policies and the World Economy, 2nd ed. (Massachusetts: The MIT press).

Gardner, G.W. and K.P. Kimbrough, 1989, The behavior of U.S. tariff rates, American Economic Review 79, 211-218.

Gardner, G.W., D.J. Slottje, and K.P. Kimbrough, 1992, Tariff behavior in five European countries, Economics Letters 39, 73-78.

Gavin, M., 1991, Tariffs and the current account: On the macroeconomics of commercial policy, Journal of Economic Dynamics and Control 15, 27-52. 
Ikeda, Shinsuke, 2000a, Weakly nonseparable preferences and the Harberger-Laursen-Metzler effect, forthcoming in Canadian Journal of Economics.

Ikeda, Shinsuke, 2000b, Luxury and wealth accumulation, unpublished.

Judd, K.L., 1985, Redistributive taxation in a simple perfect foresight model, Journal of Public Economics 28, 59-83.

Lucas, R. and N. Stokey, 1984, Optimal growth with many consumers, Journal of Economic Theory 32, 139-171.

Mansoorian, A., 1993, Tariffs, habit persistence, and the current account, Canadian Journal of Economics 26, 194-207.

Obstfeld, M., 1990, Intertemporal dependence, impatience, and dynamics, Journal of Monetary Economics 26, 45-76.

O'Rourke, K., 1989, Tariffs and the current account with short-run capital specificity, Economics Letters 30, 67-70.

Ostry, J.D., 1990, Tariffs and the current account: the role of initial distortions, Canadian Journal of Economics 23, 348-356.

Ostry, J.D. and A.K. Rose, 1992, An empirical evaluation of the macroeconomic effect of tariffs, Journal of International Money and Finance 11, 63-79.

Razin, A. and L.E.O. Svensson, 1983, Trade taxes and the current account, Economics Letters 13, 55-57.

Sen, P. and S.J. Turnovsky, 1989, Tariffs, capital accumulation and the current account in a small open economy, International Economic Review 30, 811-831.

Shi, S., 1994, Weakly nonseparable preference and distortionary taxes in a small open economy, International Economic Review 35, 411-428.

Svensson, L.E.O. and A. Razin, 1983, The terms of trade and the current account: The Harberger-Laursen-Metzler effect, Journal of Political Economy 91, 97-125. 
Turnovsky, S.J., 1991, Tariffs and sectoral adjustments in an open economy, Journal of Economic Dynamics and Control 15, 53-89.

Uzawa, H., 1968, Time preference, the consumption function and optimum asset holdings, in: J.N. Wolfe, ed., Value Capital and Growth: Papers in Honour of Sir John Hicks (Chicago: Aldine).

Van Wijnbergen, S., 1987, Tariffs, employment and the current account: Real wage resistance and the macroeconomics of protectionism, International Economic Review 28, 691-709. 


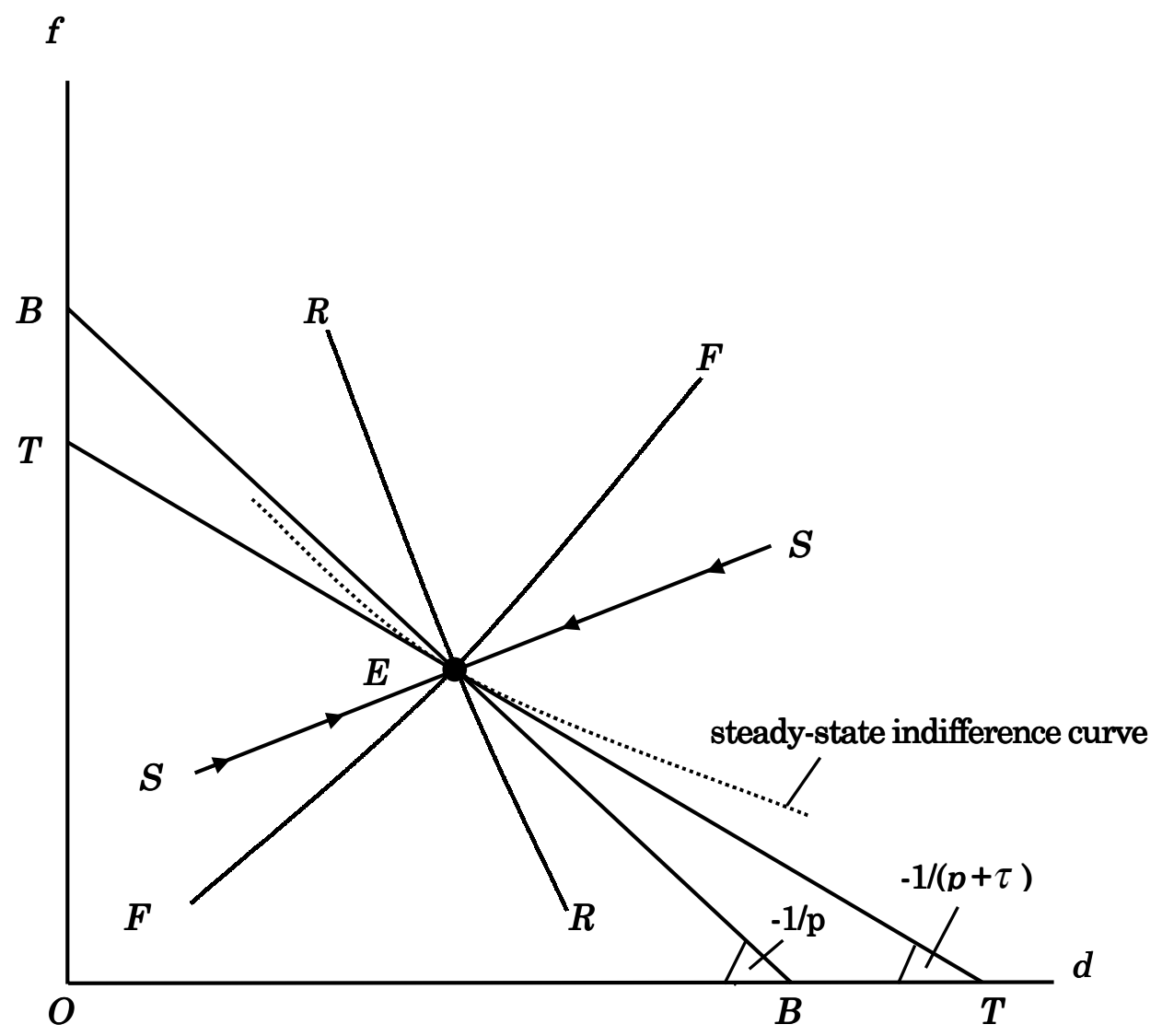

Figure 1. Equilibrium under Tariffs: $\xi>0, \theta_{d} / \theta_{f}>1 / p$. 


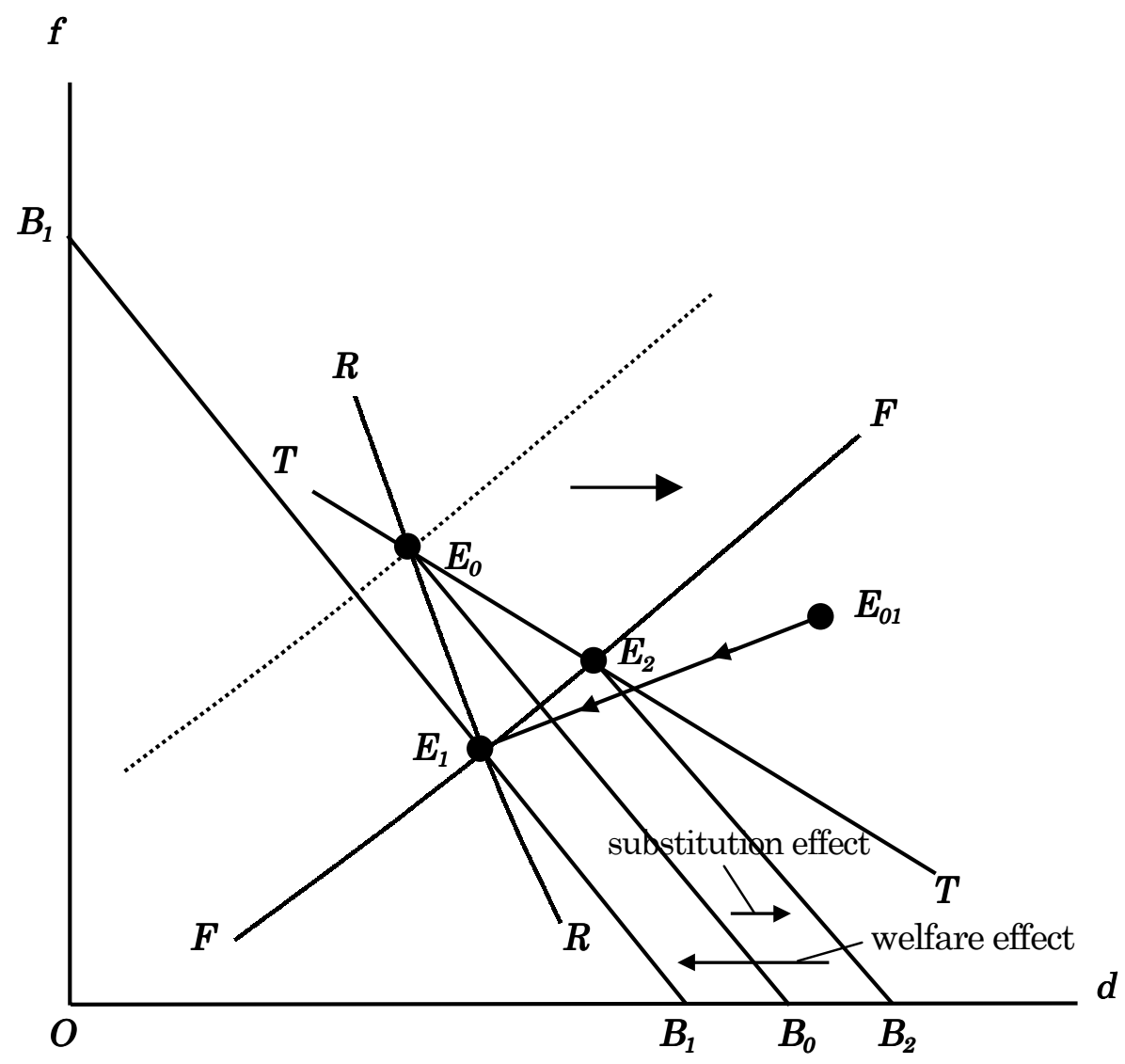

Figure 2. An Increase in Tariffs: $\theta_{d} / \theta_{f}>1 / p>1 /(p+\tau)$. 